Rel. Stud. 35, pp. 323-345. Printed in the United Kingdom (C) 1999 Cambridge University Press

\title{
The problem of evil and moral indifference
}

\author{
TIM MAWSON \\ Keble College, University of $O x$ ford, $O X_{I}{ }_{3} P G$
}

\begin{abstract}
In this paper, I argue that if the libertarian free will defence were seen to fail because determinism were seen to be true, then another solution to the problem of evil would present itself. I start by arguing that one cannot, by consideration of agents' choices between morally indifferent options, reach any conclusion as to these agents' moral qualities. If certain forms of consequentialism were false, determinism true, and if there were a God who chose to create this universe, then His choice would have been between such options. Consideration of the general nature of the universe God putatively chose to create would not then license any conclusion as His moral qualities.
\end{abstract}

I

The ultimate Author of all our volitions is the Creator of the world, who first bestowed motion on this immense machine, and placed all beings in that particular position, whence every subsequent event, by an inevitable necessity, must result. Human actions, therefore, either can have no moral turpitude at all, as proceeding from so good a cause; or if they have any turpitude, they must involve our Creator in the same guilt, while he is acknowledged to be their ultimate cause and author. For as a man, who fired a mine, is answerable for all the consequences whether the train he employed be long or short; so wherever a continued chain of necessary causes is fixed, that Being, either finite or infinite, who produces the first, is likewise the author of all the rest, and must both bear the blame and acquire the praise which belong to them. ${ }^{1}$

The problem of evil is the philosophical or theological problem of how to resolve the conceptual tension between two beliefs: firstly, that the universe was created by a God who is both omnipotent and perfectly benevolent, and secondly, that the universe contains evil. Within the community of those who wish to hold both beliefs (classical theists), emphasis is usually placed on what has become known as 'the free will defence'. Roughly speaking, this suggests that evil is a necessary accompaniment to free will; a universe with free will is morally better than one without; and therefore the free will we (and perhaps other creatures) enjoy in our universe makes the evil in it morally worthwhile. The free will defence may be thought untenable on a variety of fronts, but one of the most serious attacks - which Hume no doubt would have pressed - threatens the libertarian conception of free will on which the defence is characteristically based. In this paper, I shall explore

\footnotetext{
${ }^{1}$ David Hume An Enquiry Concerning Human Understanding, section VIII, part II.
} 
how, if an attack of this sort were successful, classical theists could fall back to a position from which Hume could not so readily dislodge them. ${ }^{2}$

\section{I}

The gifts of time, knowledge and intellect which we can bring to our moral deliberations are regrettably finite, and this no doubt explains many of those occasions when, having been presented by our circumstances with a choice between various mutually exclusive courses of action available to us, we cannot decide which one we ought to pursue. However, it is not a necessary truth that the question 'What ought I to do?' always has an answer of a nondisjunctive sort. So in some situations, if we cannot decide which one course of action it is which we ought to pursue, that should be of less concern to us. It could be that sometimes there is no one course of action which we ought to pursue. Of the courses of action available to us, two or more could be of equal moral worth and we ought to do either one or the other. Arguably, two or more courses of action could be of equal moral worth for two reasons. Firstly, and most contentiously, they could be of equal moral worth because moral distinctions and considerations were not applicable to the choice in question at all, that is each option was morally 'neutral'. Secondly, and less contentiously, options could be of equal moral worth in the more straightforward sense that the moral considerations in favour of each option were equally balanced. Consider the following three examples.

Firstly, one arrives at a cocktail party and is asked by one's host whether one would prefer a Martini, a White Russian, or an orange juice. Each drink is in plentiful supply and one will not have to drive or operate machinery later in the evening. Secondly, one is buying a new car and, having decided on the model and the price, is offered one's choice of colour: white, red, or lime green. The car is for one's own personal use, so nobody will be upset by one's decision. Thirdly, one has visited the animal sanctuary to obtain a pet and been offered either a small puppy or a goldfish. Neither of these animals will be destroyed or unhappy if one does not take it; neither would the responsibilities of owning either one of them interfere with one's other duties. In each of these three situations then, it seems reasonable to suppose either that moral considerations are not applicable or pertinent at all to the choice at hand or that any which do operate are equally balanced (or could be

\footnotetext{
${ }^{2}$ It may be that libertarianism can be shown to fail as an acceptable account of free will in ways that do not depend upon or entail the truth of determinism. (Libertarianism at least commits one to the view that not every state of the universe is entirely causally necessitated by the preceding state; some 'events' - specifically the actions of creatures with free will - are uncaused by preceding states. Presumably it also commits one to more. Determinism I take to be the theory that, possibly with the rare exception of miracles, every state of the universe is entirely causally necessitated by the preceding state of the universe.) Furthermore, the solution to the problem of evil I present may not need determinism - a rather looser regular causal structure to space-time or a commitment to what Parfit calls the 'Time-Dependence Claim' (D. Parfit Reasons and Persons (Oxford: Clarendon Press, I984), 352) might suffice. I shall not, however, explore these issues.
} 
made to balance by suitable accretion of detail). Thus, in either case, these three decisions are, or could easily be made, ones between morally neutral options or options of equal moral worth; if so, they are, or could easily be made, decisions about which one should (given perhaps suitable caveats about one's knowing that they are of equal moral worth) display moral indifference.

If one is a consequentialist, then examples of situations in which one ought to be morally indifferent between two or more courses of action might be supposed to be thinner on the ground and more difficult to detect than my comments hitherto would suggest. A consequentialist could argue that although, in my first example, it may prima facie seem a matter of moral indifference which drink one chooses, in fact - as one ought always to act so as to yield the best overall consequence and thus as moral considerations are pertinent to all choices - it is extremely unlikely that each drink option is indeed 'morally balanced' relative to the others; subtly different consequences will ensue depending on one's choice. Thus it is extremely unlikely that one ought to be morally indifferent between them. However, even if true, this would not threaten the claim that it is logically possible that two or more actions available to an agent in a situation would in fact give rise to consequences of equal moral worth, even if it would perhaps threaten the further claim - which I have hitherto inclined towards - that such situations arise as a matter of fact for many of us in our everyday lives, ${ }^{3}$ and thus I conclude that a class (albeit potentially empty) of choices between options about which it is or would be appropriate to display moral indifference, should be accepted by all moral theorists.

There are at least three things that the acceptance of the potential appropriateness of moral indifference in some choices should not be taken to mean or entail and which deserve mention at this stage.

\footnotetext{
${ }^{3}$ According to consequentialism, in a morally ideal world everyone would do those actions that did in fact result in the best overall consequences. However, in this less-than-ideal world where one is less than omniscient, one cannot ever know with certainty what the action that would lead to the best overal consequences is. Within any consequentialist moral theory, there must therefore operate a notion of what it is that one is morally justified in doing which allows that one is morally justified in doing that which it is reasonable for one to suppose is the action which will in fact give rise to the best overall consequences. The problem of the potential infinite regress of calculations - involved in deciding what it is that it is reasonable for one to suppose it is reasonable for one to suppose is the action which will in fact give rise to the best overall consequences etc. - is solved by suggesting (plausibly as an empirical truth) that a law of diminishing marginal returns operates on the process of calculation, and thus beyond a certain point the 'disutility' of the act of calculation with regard to one's reasonableness will mean that it will not be morally justifiable to perform further calculations - indeed one will be obliged to stop calculating. At this stage, it seems credible to suggest, very often one will have a number of options greater than one, each of which will seem equally likely to be that action which it is reasonable for one to suppose would in fact yield the best consequences overall. Even if one is a strict consequentialist, one might plausibly suppose that agents are very often in situations where they are presented with a number of options greater than one which appear to be of equal moral worth and at the same time that they are morally unjustified in seeking the level of moral clarity which would enable this 'probably illusory' appearance to be dissolved : i.e. agents are very often morally justified in displaying moral indifference. I think then that the consequentialist would need to accept that this type of situation arises quite often and that my three examples are cases of it.
} 
Firstly, the acceptance of the potential appropriateness of moral indifference should not be taken to mean or entail that in a situation where one chooses between two or more options which one recognizes to be morally neutral or of equal moral worth, the choice must be entirely arbitrary. As should be obvious from my three examples, when one has no more moral reason to choose one course of action rather than another, one may still have other sorts of reason. In the first case, reasons of personal taste might dictate that one opts for the Martini. In the second case, (broadly) aesthetic reasons might exclude the lime green car from one's mind as a serious option. In the third case, one might have a positive emotional reaction on seeing the puppy bound up to one and playfully nuzzle one's knee, a reaction which the goldfish - with its more limited repertoire of behaviour - cannot engender, and a reaction which serves as a reason for one subsequently choosing the puppy to be one's pet. However, having a taste for Martinis rather than White Russians, a negative aesthetic appraisal of lime green cars, or a tendency towards a certain emotional reaction when seeing puppies, are not facts about one in virtue of which one is morally better or worse than one would have been if they had been in some ways different: if one had liked White Russians more than Martinis, or lime green cars more than others, or goldfish more than puppies, one would not have been a morally better or worse person. ${ }^{4}$ One cannot be morally judged on one's preferences or choices in areas of moral indifference. This is a point to which we shall have occasion to return later.

Secondly, that there are occasionally options between which one ought to be morally indifferent should not be taken to imply that one cannot have in any sense a moral reason for doing what it is that one chooses to do in such situations, that morally speaking one's agency should grind to a halt. As well as having moral reason to confine one's choice to these morally indifferent options, one may have moral reason to do some one of those things within a certain time frame. Buridan's ass, finding itself equidistant between two equally attractive bales of straw, had (prudential) reason - which it sadly did not recognize - to choose one (prudentially) arbitrarily rather than not choose one at all and instead starve to death. So it is that, in my first example, it may reasonably be supposed to be one's (moral) obligation to make a (morally) arbitrary choice between drinks within a certain time frame so as to not inconvenience or offend one's host.

Thirdly, from the fact that one ought to be morally indifferent between some courses of action open to one in a given situation, it should not be concluded that one ought to be indifferent between all courses of action open

\footnotetext{
4 If this last remark is unacceptable, then I hope it can be seen to be a problem with my choice of examples, rather than a problem with the philosophical point which they were intended to illustrate: if one thinks it is a moral duty to cultivate certain tastes, aesthetic sentiments, or emotional reactions towards animals, then these examples would need to be complicated in order to serve their purpose or replaced with new ones. I hope it can be seen that they easily could be.
} 
to one in that situation - it should not be concluded that it is entirely up to one what it is that one ought to do. For example, even if one's choice of colour for a new car is a matter about which one should be morally indifferent, the choice whether to choose a colour or to take this opportunity to try to rob the salesman is not a choice between options about which one should be morally indifferent.

This last point might be thought too obvious to merit mention were it not for the fact that several authors draw from situations of choice - situations which, it strikes this author, they have taken unusual pains to describe in such a way as to appear morally balanced - just this sort of conclusion, the conclusion that we cannot have any knowledge of objective moral requirements and 'thus' that it is in some sense up to us to create our morality by the very act of exercising choice. In particular, I have in mind here a famous passage of Sartre's concerning a young Frenchman who is torn between staying at home to comfort his ailing mother and going to fight for France in the war. After a prolonged description of the young man's turmoil and confusion, Sartre seems to draw the conclusion that as we cannot have knowledge of a moral order existing independently of our choices to which our choices should conform, so we ought to create such an order for ourselves. He uses the intuition that morality ought to tell us what to do in any situation, and runs it up against a situation in which there seems to be no one thing which we can without qualification say morality tells us that this man ought to do, to generate a movement from the resulting confusion and epistemic scepticism about this particular case to a scepticism about the ontological status of moral requirements in general and in turn to an existentialist meta-ethic.

In my experience, if narrating Sartre's story to a pupil, it can readily be expanded in the light of any strong intuitions that are forthcoming from him or her that the man's duty to his mother quickly and without problem overrides that to his country or vice versa. One can vary the severity of the mother's illness and/or the state of the war through a continuum to ensure balancing and one can also easily ensure that the possibility of compromise is removed by specifying in a number of more or less ad hoc ways how it is that this man cannot contribute to the war effort from his mother's bedside, cannot leave her with other relatives, and so forth. If one so tells the story, one can be assured that - as a matter of fact - the question 'Should this man abandon his duty to his country or should he go against his mother's wishes?' will yield confusion or scepticism about (at least some) moral knowledge in one's pupil: it strikes me that - as a matter of philosophy - it should not, and thus Sartre's argument can be stopped at the first stage. ${ }^{5}$

The correct answer to the question of what this man ought to do would

${ }^{5}$ Of course, it can also be stopped at nearly every other stage as well. 
be one which simply acknowledged that this man's duty has a disjunctive nature: he should either go to war or he should stay with his mother, but as the story has been intricately set up to ensure that these options are morally balanced - the man should be morally indifferent between them. It is not then that morality gives us no answer as to what this man ought to do: the answer morality gives us is that there is no one thing which he ought to do. It would be a good thing for him to fight for his country (in itself) and it would be a good thing for him to stay at home and comfort his mother (in itself). Each of these things is, in this situation, ex hypothesi equally good. Sadly, he cannot do both. Thus he is morally free to choose which of these two options he likes for non-moral reasons or even entirely arbitrarilymorally free in that he cannot be praised or blamed whichever way he chooses. Importantly, and this is a point that Sartre seems to overlook, he is not morally free to choose between all options available to him: he cannot (morally) decide to escape to Switzerland for the duration of the war, abandoning both his country and his mother. That he should display an attitude of moral indifference to those particular options to which he is objectively morally restricted is itself not a matter of moral indifference; it is an objective moral requirement to which his choices should conform or, more cautiously, Sartre has given us no reason to doubt our pre-reflective intuition that it is such a requirement. ${ }^{6}$

It is worth noting again that, supposing Sartre's story to be historically true, these two courses of action really were morally balanced relative to one another; this man knew with certainty that they were; and he chose one of them. Although we can praise the Frenchman for having chosen one of the two options to which he ought to have confined himself (rather than having run off to Switzerland) we cannot praise him more or less for having chosen the particular one of these two options which he did. Had he chosen the other, he would have been equally praiseworthy. As we observed earlier, an agent who chooses between options which he or she recognizes as morally indifferent for non-moral reasons, or for no reasons at all, cannot appropriately be praised or blamed for his or her choice, although, of course, he or she can be praised for restricting his or her choice to these options, if he

\footnotetext{
${ }^{6}$ If this man ought to be morally indifferent between these two options and if it is not a matter of moral indifference that he ought to be morally indifferent between just these two options, it may thus be that there is nothing which he can do to get there to be just one thing which he ought to do. Alternatively, and as perhaps a small concession to Sartre, it may be that there is. It is possible to imagine the Frenchman of this story saying to his mother 'Ge promets de rester auprès de toi jusqu'à la fin de la guerre' and thereby ensuring that he now ought to do so. What was a choice between morally indifferent options would thus have become a choice between morally different ones. But no agent, in situations which would otherwise be of choice between options of equal moral worth, can be under any obligation to generate obligations for himself or herself like this; and, although one could always reduce one's duty from a disjunctive state in this manner, firstly, this is not the routine which Sartre seems to have in mind, and secondly, creating morality for oneself by choosing what to promise oneself and others can only work in the relatively smal areas of choice where, without such promising, one ought to be morally indifferent; the demarcation of those areas is not itself something which can be done by such a procedure.
} 
or she believed that he or she ought to do one of them, or of course blamed, if he or she believed that neither of them was one which he or she ought to do. A consequence of being appropriately morally indifferent between two or more actions is then that one cannot be reasonably praised or blamed whichever of those actions one does in fact take.

I shall close this section by describing in general terms what I suggest is a necessary condition for reasonably blaming an agent for a choice of his or hers. ${ }^{7}$ I concentrate on the notion of blaming, although a parallel argument could be advanced using that of praising, and I suggest that in a situation where no one would actually satisfy the condition for reasonable praising or blaming, regardless of which way a particular agent chose, that agent ought to be morally indifferent about that choice. ${ }^{8}$

It seems plausible to suppose that it is a necessary condition of one's reasonably blaming an agent on one's own behalf for an action which he or she has performed, that the action in question intentionally brought about (is bringing about/will bring about) a situation in which one has actually been put (is being put/will be put) at a disadvantage relative to that state in which one would have been (would at some future time be in) had that agent taken another course of action which was open to him or her. If one has not actually been in any way disadvantaged by the action, what is it that one is complaining about (on one's own behalf)?

It is certainly true that one could satisfy this condition, yet not be reasonable in blaming the agent on one's own behalf, ${ }^{9}$ and so its being true that one

\footnotetext{
7 There are certainly cases where it would be impossible to reasonably praise or blame an agent even though he or she ought not to have been morally indifferent. For example, agents can, with the best of intentions, make 'honest' mistakes leading to them perform wrong actions for which they are not culpable. Alternatively, with the worst of intentions, agents can inadvertently do the 'right' thing in a broad sense of the term. But these situations, although no doubt more common for us, are less relevant to the case of an agent who, being omniscient, would never make such mistakes, and it is such an agent who will occupy our attention in the next section. For similar reasons, I shall simplify my discussion of the suggested necessary condition of reasonably blaming someone in the main text that follows. As I discuss it, it may seem to rule out reasonably blaming people in some cases of negligence where we would most naturally take them to be culpable. To expand on these side issues here would detain me too long from my main purpose.

${ }^{8}$ When one is faced with a choice between performing and not performing a supererogatory act, although one cannot be reasonably blamed for one's choice whichever way one chooses - given that supererogatory acts are by definition good acts the omission of which one cannot be blamed for - one can be reasonably praised if one performs them and one ought not to be morally indifferent about whether or not to perform them. Thus that one cannot be blamed whichever way one chooses does not entail that one cannot be praised, nor that one ought to be morally indifferent. I do suggest however that if one cannot be praised or blamed whichever way one chooses, then one ought to be morally indifferent, and that if one ought to be morally indifferent, then one cannot be praised or blamed whichever way one chooses.

${ }^{9}$ If we consider again the Frenchman who, having anguished for a suitable time about whether to go and assist his country in the war or stay at home with his ill mother, let us say, decided to go and fight, we can see that, although his mother was then at a relative disadvantage as a result of his choice (had he chosen to stay with her she would have been better off), she could not reasonably complain that he had not acted as he ought; she could not blame him for his choice. Although she satisfied the necessary condition for reasonably blaming him, no doubt we incline to think that the mother would have been acting unreasonably if she had blamed her son because, however the son had chosen (between these two
} 
could have benefited from an agent's acting differently should be understood as a necessary condition for reasonably blaming on one's own behalf and not itself a sufficient condition; but equally, as the examples later ought to make clear, it is very plausible to suggest that, as long as 'benefit' is interpreted broadly, it is a necessary condition and so I shall not undertake a lengthy defence of it. As well as blaming someone for a wrong done to oneself, one often feels the, in some sense more principled, need to blame someone for a wrong done to others. In the light of this, an easy adaptation of the above would give rise to the following as a necessary condition of being blameworthy for an action.

For an agent to be blameworthy for an action which he or she has performed, the action in question must have intentionally brought about a situation in which someone actually has been/is/will be at a disadvantage relative to that state in which he, she or it would have been in/would be in now/would be in the future, had that agent taken another course of action.

Again, I suggest this only as a necessary condition for an agent to be blameworthy and not as in itself sufficient. Let us briefly consider three examples of this condition 'at work'.

Firstly, one's bank levies its annual $£ 5$ administrative charge on one's account as one had freely agreed that it might when opening that account. Although one is thus worse off - by $£ 5$ - than one would have been had the bank not so acted (and thus satisfies the necessary condition for reasonably blaming it), one cannot reasonably complain, as the bank has the right to make such a charge in virtue of, if nothing else, one's having freely agreed to its doing so. Secondly, a man surreptitiously removes a $£ 5$ note from one's jacket pocket as one is walking down the street. Again, one is thus $£ 5$ worse off than one would have been had things been different. In addition, we may plausibly add, one had not agreed to this man's actions: therefore, it would be quite reasonable for one to blame him for his action - his action is indeed a theft. Thirdly, one notices a man surreptitiously removing a $£ 5$ note from one's sister's jacket pocket as she is walking down the street and replacing it with a $f_{\mathrm{I}} \mathrm{o}$ note. Here there is perhaps more room for disagreement about whether or not it would be reasonable for one or one's sister to blame the man. On the one hand, it could be argued that one's sister is not worse off, but better off (by $£ 5$ ) than she would have been had this man not so acted, and thus the man cannot reasonably be blamed for his action. On the other hand, it could be argued that she is worse off as the invasion of her privacy outweighs the financial gain, and thus one could reasonably blame him for his action on her behalf or she could reasonably blame him on her own

options), some person or entity would have satisfied this condition (his mother or his country). So one can be blameless in one's actions even when, as a result of them, someone satisfies the above mentioned necessary condition for reasonably blaming one for them. 
behalf. Whichever way one's intuitions push one on this ethical question, I hope it can be seen then that they cannot call into question the meta-ethical principle endorsed above, that - as long as benefit is broadly interpreted it cannot be reasonable to blame someone for an action of theirs if no one actually would have benefited from their acting differently.

I now suggest then that it is a sufficient condition of being in a situation where one ought to be morally indifferent between two or more options that, whichever of these options one chose, no one would actually be worse off than they would be if one took another: if one finds oneself in a situation where, whichever of two or more options one takes, no one would actually be worse off than they would be if one took another, then one ought to be morally indifferent between them - one will be equally praiseworthy whichever way one acts.

In this section, I hope then to have elaborated on and rendered plausible the suggestion that there are or could be situations where an agent was presented with an obligation of a disjunctive sort, leaving him or her with a choice between two or more options of equal moral worth (and hence between which he or she ought to display moral indifference) and that in those situations, assuming the agent confines himself or herself to these options, he or she cannot be morally more praiseworthy or blameworthy for his or her choice, however he or she makes it. Hence someone witnessing such a choice could not conclude anything about the moral qualities of the agent, other than by knowing that the agent had chosen to restrict himself or herself to those options, a restriction which itself could be a reason for praise or blame. I also hope to have made plausible, although not defended at length, the suggestion that if no one would actually in any sense benefit from an agent's choosing one option rather than another, then that agent ought to be morally indifferent about which of these options he or she selects.

In the next section, I shall go on to apply these suggestions to the situation of choice which classical theism depicts God as having faced in creating this universe. ${ }^{10}$

I I I

Classical theism asserts that there is a perfectly good God who chose to create this universe. He may or may not have created other universes, but in no sense (other perhaps than those we are about to examine) was He compelled to create this universe or others: if He had chosen to do so, He could have remained the sole existent. Thus it is that we may sensibly inquire whether if classical theism were true, God's choice to create or not to create would

\footnotetext{
${ }^{10}$ I talk, for ease of presentation, of God as a 'He' and of His choice as one that occurred inside time. I hope it can be seen how, with only stylistic difficulty, the points I make could be transposed into the versions of classical theism which alter these assumptions.
} 
have been a choice between morally indifferent options. We may then, somewhat artificially but for ease of analysis, split our inquiry into two stages. Firstly, in choosing to create any universe at all rather than remain the sole existent, ought God to have displayed moral indifference? And secondly, in choosing whether or not to create this particular universe, ought God to have displayed moral indifference? Given, what is rather obvious, that this universe exists, what may be less obvious is that our answers to these questions will have important consequences for the plausibility of classical theism.

With regard to the first question, if we were to discover that if God were to exist, He ought not to have been morally indifferent in choosing to create a universe rather than remain the sole existent, this could only be for two reasons. Firstly, it could be because if there were a God, He would have been under an obligation to create at least one universe and then the way might be open for classical theists to use the mere fact that a universe exists as evidence of God's goodness and hence in support of their position. Secondly and on the other hand, it could be because if there were a God, He would have been under an obligation not to create any universe and then a parallel argument might undermine the credibility of classical theism by using the mere fact that a universe exists as evidence that any God responsible for it must be morally bad. However, if we were to discover that if God were to exist, then He ought to have been morally indifferent about whether or not to create a universe, we could not use the mere fact that a universe exists as evidence of His moral character and thus as supportive or undermining of classical theism at all.

Matters are similar with regard to the second question. If we were to discover that if God were to exist, then He ought not to have been morally indifferent in choosing whether or not to create this particular universe, rather than some other one (or none at all), this could be for two reasons. Either it could be because if there were a God, He would have been under an obligation to create this particular universe and then we might perhaps think that the door was open to arguments which used the fact that this universe exists as evidence in favour of God's goodness and thus in support of classical theism. Alternatively, it could be because if God were to exist, He would have been under an obligation not to create this universe and then we might think that the parallel argument using the fact that this universe exists as evidence against God's goodness and thus against classical theism could be advanced. Again however, if we were to discover that if God were to exist, then He ought to have been morally indifferent about whether or not to create this particular universe, argumentation in either direction would be forestalled.

I shall argue that, given the falsity of certain forms of consequentialism and the truth of determinism, God ought to have been morally indifferent about both questions : the existence of this or any other deterministic universe 
cannot be evidence of the moral qualities of God and through being so evidence which should increase or decrease the probability of classical theism. ${ }^{11}$ Given the conditions described in section II, this argument can now proceed quite quickly.

Let us take the first question first. In choosing whether or not to create any universe at all, ought God to have displayed moral indifference? Prior to the creation of a universe, there were, ex hypothesi, no other creatures around to whom God could have obligations in the sense that they could either benefit or suffer from the continuing absence of a universe or from its creation. In particular we, as not yet existing, were not in a better or worse state than we are now - a state the improvement or diminution of which God could effect by bringing us into existence. As it is logically impossible for anyone who actually exists to be better off, equally well off, or worse off than if they had never existed, so it is logically impossible for anyone who does not exist to be better off, equally well off, or worse off than someone who does. We were not in a better or worse state prior to the creation of the universe not then because we were in the same state, but because we were not in any state - we did not yet exist. ${ }^{12}$ And although one may have obligations to those that do not yet exist, unless one is a peculiar shade of consequentialist, one cannot have obligations to bring them into existence. Given the falsity of certain forms of consequentialism then, God cannot be said to have had a moral reason for creating a universe rather than not creating one. Given the choice whether to create any universe at all or whether to remain the sole existent, He should have been morally indifferent. ${ }^{13}$ Thus, given the falsity of certain forms of consequentialism, we cannot use the mere fact that $a$ universe exists as evidence of God's (moral) character and through doing so as evidence in favour of or against classical theism.

The most analogous earthly situation I can think of is that of the choice, which I imagine most married couples face, of whether or not to have a child. If one were to carefully specify various conditions (that there are no health risks involved in the mother conceiving, that having a child would not be financially ruinous to the couple or in some other way reduce their ability to meet their obligations etc.), then it seems reasonable to me to suppose that there is no obligation on a couple which fulfills those conditions to either produce or refrain from producing a child: they ought to be morally indifferent. If this is true, then from the fact that such a couple chose to have a child, one would not be able to infer that it was more likely that they were

\footnotetext{
11 The 'through being so' here is intended to ensure that I am not taken to be asserting that the existence of this universe cannot increase the probability of classical theism in some other way; I leave open the possibility that, for example, the cosmological argument might be made to work.

12 See the Appendix for a defence of this point.

13 Of course, given the first caveat on what moral indifference should not be taken to mean or entail as described in section II, this should not be taken to imply that one must therefore conclude that $\mathrm{He}$ had no reason at all to create a universe. He could have had aesthetic reason.
} 
morally better or worse than if they had chosen not to do so. One would not be able to use the fact that $a$ child was brought into existence as evidence in favour of or against the hypothesis that the parents were perfectly (morally) good. (No doubt, in the case of human parents, one would be able to use other facts as evidence against this hypothesis.) This example is the closest analogy for me. If, unlike me, one thinks that married couples are obliged to try to conceive children, then one might find a more analogous situation in that of a farmer choosing whether or not to breed animals (let us say, to avoid other ethical issues, not for their meat) or grow wheat on his land. Again, if one carefully accumulates sufficient conditions (such as supposing the farmer to have land and buildings equally suited to both), it seems to me that one can generate a description of a situation in which the farmer ought to be morally indifferent about whether or not he breeds animals on his land or leaves it devoid of animals and grows wheat on it instead. If this is true, then the fact that a farmer who met these conditions chose to breed animals would not license us to judge him as morally better or worse than if he had chosen to fail to do so and instead planted wheat. The farmer who creates animals (his actions, accompanied of course by those of some of the animals themselves, produce animals which would not otherwise have existed) is not ipso facto morally better or worse than the farmer who does not create animals but creates wheat instead. The presence or absence of such living creatures on farmed land cannot be used as evidence in favour of or against the hypothesis that the farmer in charge of that land is perfectly (morally) good.

Turning to the second question, what about the creation of this particular universe? Would this be something which God had more or less (moral) reason to do than not to do?

Given the principles endorsed in section II, to reasonably blame God for creating this universe it must at least be the case that His act of creation intentionally brought about a situation in which someone actually has been/ is/will be at a disadvantage relative to that state which he, she or it would have been in/would be in now/would be in the future, had God not created this universe, but created another instead; had He exercised the option to create no universe, obviously no-one could have benefited as no-one would have existed. Given this, and (what amounts to the same thing, as we shall shortly see) given again the falsity of some forms of consequentialism, God ought to have been morally indifferent about a choice between remaining the sole existent or creating a universe or universes in which all of its/their creatures were at least as well off as they would have been in any other possible universe in which God might otherwise have created them. God ought to have been morally indifferent about a choice between whether or not to create one or more universes of the sort which are the best of all possible universes for all of their residents. 
God ought to be morally indifferent about whether or not to create one or more universes of the sort which are the best of all possible universes for all of their residents as, if $\mathrm{He}$ were to create a particular universe or particular universes like this, none of the creatures in it or them could reasonably blame Him for creating them in the situations they find themselves because none of them could have benefited from God acting differently. None of them could have benefited from His acting differently as if $\mathrm{He}$ had created another universe, He would have created one in which, ex hypothesi, they would be less well off, or equally well off, or non-existent. ${ }^{14}$ And, in any of these cases, none of them would have benefited from His so acting. Given then that God ought to have been morally indifferent about whether or not to create any, some, or all universes of this sort, one could not, from knowing simply that a universe of this sort existed, form any reasonable judgement about God's moral character - other perhaps than by knowing that it was praiseworthy of Him to confine Himself to actualizing one of these 'best-of-all-possibleuniverses-for-all-of-its-residents' options. If ours were a universe like this, then God ought to have been morally indifferent about creating it, and thus we could not use the existence of this universe as evidence of God's moral character, other perhaps than by its being evidence that He had chosen to confine Himself to actualizing a universe of the best-of-all-possible-universesfor-all-of-its-residents type. Given determinism, it is plausible to suggest that ours is a universe like this.

If our universe is deterministic, then (per impossibile, I shall argue) for God to have put any of us in a better situation than that in which we in fact find or shall find ourselves would require him either to effect a change in the initial conditions of the universe and/or the laws of nature operating on them or to perform miracles in the Humean sense of interrupting its deterministic development at later times. Considering these options in reverse order, miraculous intervention whenever something less good than the best thing which logically could happen to a creature was about to happen would lead to such a breakdown in the laws of nature - one might think particularly of the biological laws of evolution, red in tooth and claw - as to be straightforwardly incompatible with determinism. Given the assumption of the truth of determinism under which we are working, this can therefore be ruled out. ${ }^{15}$

\footnotetext{
14 Since writing the first draft of this paper, it has been pointed out to me that a similar argument to this is presented by R. M. Adams in 'Must God create the best?', Philosophical Review, 8I (I 972), 3I 7-332.

15 I do not intend to assert that determinism cannot be understood as being compatible with some Humean miracles, just not this many. This raises the question of whether God ought to do more miracles than, on any plausible account, He seems in fact to be doing. Presumably, there are a large number of borderline cases involving God performing so many miracles that it becomes indeterminate whether or not the universe is deterministic. However, it seems intuitively plausible to suggest that our ex hypothesi deterministic universe is not close to any of these. Is God not then under an obligation to do more miracles than He seems to be doing? It must be admitted that (a) a negative answer to this question is needed, and (b) some work would need to be done to provide one. I can only plead space considerations as a justification for not undertaking such work here. However, if we allow ourselves to assume for the moment that this work could be successfully completed, we may observe that it would leave pressing the question
} 
On the other hand, and turning to the first option, scientific discoveries as to the simplicity and 'fine-tuning' of the universe - both in the nature and arrangement of its fundamental particles at its earliest stages - seem to suggest that any changes in them would cause far more effects than those which we might envisage as being desirable. Plausibly even the tiniest change in the laws of nature or in the initial conditions would causally entail that stars and planets could never form. And a universe in which stars and planets never formed would be a universe in which creatures, in any sense we know of, never formed, in which no humans ever formed, and hence in which no one would be better off than he or she would have been had such a change in the laws of nature or initial conditions of the universe not been effected. The only way for God to avoid the causally necessitated lack of stars, planets, creatures and humans would be for Him to constantly miraculously interrupt such a universe's deterministic development, but, given our assumption of determinism, we have ruled this option out. A different deterministic universe with different laws and different particles could not contain humans. Hence we humans could not, of logical necessity, have benefited from God's having created another universe; we would not have existed. God could not have created any of us in a better deterministic universe than that which we find ourselves in. This is the best of all possible universes for us. It is also, by a parallel argument, the worst of all possible universes for us; thus we cannot praise God for 'confining' His choice. Given then that we could neither be better off nor be worse off, whether or not God had created this universe, and neither of course could any other creature, God cannot then be said to have had a moral reason for creating this universe rather than not creating it. Given the choice whether to create this universe or whether to create another or none at all, He should have been morally indifferent. Thus we cannot use the fact that this universe exists - we cannot use the amount of good or bad which befalls creatures in this universe - as evidence of God's moral character and through doing so as evidence in favour of or against classical theism.

Returning to our earthly analogies, it is, no doubt, a common feature of the experience of parents that their children, once they reach a certain age, make indignant protests to them about the poor supply of food, toys, pocketmoney etc. and one understandable response which many parents make simply points to the fact that the child would not have existed at all if it had not been for them. Whatever can be said about the philosophical merits of this response, what would, I think, be sufficient to silence any rational complaints of this sort (though not necessary) would be if the parents could

as to how God does manifest His benevolence if not in the creation of the universe nor - save perhaps in the occasional miracle - in its operation. Some discussion of the afterlife, it would seem, must ultimately be entered into. This issue is further discussed in the Appendix. 
truthfully point out that in fact they had done the best it was actually possible for them to do for the child - that if they had taken any other course of action, the child would not have existed at all, but perhaps another child would have existed in its place. Similarly with the farmer, if we imagine a situation in some ways similar to that posited by Orwell in Animal Farm, the animals might complain that they could conceive of the farmer making the grass greener on their side of the fence and so forth. They might then blame him for not having effected such improvements in their living conditions. But if the farmer could truthfully reply to any such complaint made by the animals that in fact it simply was not the case that any of the animals would actually have benefited by the farmer acting differently, because if he had acted differently, they would not have existed at all (rather perhaps some other animals would have existed in their place), then to be rational the animals ought to withdraw their complaint.

So, on the assumptions indicated above, the argument advanced would suggest that we should consider ourselves in our relation to God as analogous to such children in relation to their parents or such animals in relation to the farmer who created them. Doing so should silence any tendency we might feel to blame Him for the bad things which must necessarily befall us in this life or to take the badness of these things as evidence that either He does not exist or He is not perfectly good.

I V

Finally, the falsity of at least some forms of consequentialism has been assumed in order to enable me to reach my conclusion and it is thus worth pointing out, before I conclude, how my argument crucially depends on this assumption and how this assumption could be defended by the classical theist.

If one is a consequentialist, then God presumably, like all other agents, ought always to bring about the best state of affairs that He can. However, what this is taken to entail will depend on at least two things. Firstly, it will depend on whether one's consequentialism is 'positive' or 'negative' - i.e. whether it characterizes the best state of affairs primarily by reference to the amount of good or the amount of bad it contains and thus whether it dictates that agents should maximize the good or minimize the bad. Secondly, it will depend on what status, if any, one gives to creatures who do not yet exist and/or would not exist depending on what course of action is taken. Some forms of consequentialism would deny that the necessary condition for reasonable blame as I give it is indeed necessary, replacing it with the principle that one can blame an agent for an action even if any alternative action performed by that agent would not have benefited any creature that actually existed, exists or will exist, but would have benefited creatures 
who would (as a result of those actions) then have existed, and would have created more benefit overall. Parfit supports such a form of consequentialism by using several examples of choices which we might face where, even though we would seem to satisfy the sufficient condition for moral indifference as I have given it, it is not obvious that we ought to be morally indifferent: indeed to Parfit it is obvious that we ought not to be morally indifferent. One such example is that of a choice between depleting or conserving the earth's resources. ${ }^{16}$ The important feature of such a choice to our discussion is that - given his 'Time-Dependence Claim' - by the time the bad effects of a policy of depletion come to be felt, no-one who then exists would have existed had a policy of conservation been followed instead. Thus the people suffering in a grossly depleted world could not have benefited from earlier conservation as, had this path been taken, they would never have existed. Adopting Parfit's form of consequentialism would enable us to justify a preference for conservation over depletion and this is what he proposes we do. However, it is possible for the classical theist to justify his or her preference for conservation over depletion (if this is the preference he or she has) without adopting a form of consequentialism that would vitiate my argument.

Given that classical theists are defined by their belief in an everlasting God, it is open for them to suggest that it is simply not true that, by the time the bad effects of a policy of depletion come to be felt, no-one who then exists would have existed had the policy of conservation been followed instead. God will exist regardless of which policy is followed and, the classical theist may maintain, He would be wronged if one depleted the earth's resources. He has forbidden such things and thus one ought not to be morally indifferent about them. One has wronged someone, in a sense made them 'worse off', if they have, from a position of authority, given an instruction on what would otherwise have been a morally indifferent issue and have had that instruction ignored. The classical theist can assert that God has issued some instructions about what is to constitute appropriate use and inappropriate abuse of His creation and, in virtue of the moral indifference of the issue (logically) prior to his doing so and His being the creator of the universe, $\mathrm{He}$ has the authority to create obligations of stewardship towards it in this way. This 'partial divine command theory' would remove the need for an acceptance of the form of consequentialism internecine to my argument (by providing a solution to what Parfit calls 'the identity problem') and, despite its rather ad hoc patchwork feel, can obviously be adapted to meet any new objections to my argument from this quarter.

If one were to hold to 'positive' consequentialism, if one were to think that agents should maximize good states of affairs and understood good states of

16 Parfit Reasons and Persons, 36 I. 
affairs as in part good states of persons who may not actually ever exist if agents do things less good than they could do, then one would have difficulty avoiding the counter-intuitive result in this context that God would be morally obliged to create all universes which were not totally bad, to create all creatures who did not totally and unremittingly fail to be fulfilled etc. (wherein 'etc.' are whatever predications seem appropriate to one's conception of the good life). Thus God would be morally obliged to create this universe as it contains at least some such creatures who would not exist in any better condition in any other universe in which God could have created them. On the other hand, if one were a 'negative' consequentialist, if one held to the amended principle of reasonable blame and thought that agents should eliminate bad things, then a parallel argument would yield the conclusion that God ought to have refrained from creating any universe that was not perfectly good in the sense of being the best of all possible universes for the best number of the best of all possible creatures. Thus, He ought not to have created this world. Non-theistic versions of these arguments can be advanced for human parents obliging them either to procreate ceaselessly or never. Each of these versions of consequentialism is, I suggest, implausibly extreme. $^{17}$

The most favourable course between the Scylla and Charybdis of these alternatives for those who accept the amended principle would lead to God's being morally obliged to create all universes which are (overall) good; obliged to restrain Himself from creating all those which are (overall) bad; and obliged to be morally indifferent only about the creation of those universes which are equally balanced. If one were a consequentialist of this shade but also believed classical theism to be true, this would commit one to asserting that the amount of good in this universe equals or exceeds the amount of bad, employing a principle of commensurability between various goods and 'bads' such that one could in principle trade one off against the other, or at least a principle by which higher order goods made lower order 'bads' worthwhile. This is the realm of traditional theodicy. My argument has been to the effect that if one accepts determinism, there is no reason to enter it. Without the principle that one can reasonably blame an agent for an action even when that action has not harmed anyone who actually has existed, exists or will exist - a principle which amounts to a form of consequentialism and a principle which the classical theist can never be forced to accept by his or her intuitions about depletion versus conservation etc. - one should suppose that God ought to have been morally indifferent about the creation of our deterministic universe.

\footnotetext{
${ }^{17}$ Of course the statement that God ought to have created only the best of all possible worlds is one expression of the problem of evil. In the context of my argument it is ruled out as false by the rejection of the form of consequentialism which would be needed to support it: the weaker principle that God ought to create (if He creates any universe at all) only universes of the sort that are the best of all possible universes for all of their residents, can be accepted.
} 
The basic structure of my argument has been:

( I) No agent can be properly praised or blamed (morally assessed) for choices made between morally indifferent options.

(2) Given the truth of determinism $(D)$, this universe $(\mathrm{U})$ is a member of the set of best-of-all-possible-universes-for-all-of-its-residents (SOBUFAR).

(3) Given the falsity of at least some forms of consequentialism $(\sim C)$, God's choice between actualizing any particular member(s) of SOBUFAR and not actualizing any member of SOBUFAR is a choice between morally indifferent options.

(4) Given $D$ and $\sim C$, God's choice between actualizing $\mathrm{U}$ and not actualizing $\mathrm{U}$ is a choice between morally indifferent options.

(From 2 and 3 )

(5) Given $D$ and $\sim C$, God cannot be praised or blamed (morally assessed) for actualizing $\mathrm{U}$.

(From I and 4)

Thus I conclude that, given the truth of determinism and the falsity of some forms of consequentialism, God would have satisfied (at the moment of His choice whether or not to create this universe) a sufficient condition for being morally indifferent; whichever way He decided, He could not fail to do for any creature who would actually exist the very best that He could. Thus, in choosing to create this universe, He cannot be more morally praiseworthy or blameworthy than He would have been had He not done so. That this conclusion has been reached without examining the nature of this universe, in particular without looking at how much good or bad it contains, shows us that, given these assumptions, the amount of good or bad which occurs in the universe should not be taken as evidence that God is either good or bad and should not affect the probability of classical theism. If one holds to classical theism and determinism, one can solve the problem of evil simply by accepting that an agent ought to be morally indifferent between two or more options when, regardless of which option is exercised, no one would actually be worse off than if another had been exercised instead: this amounts to renouncing some forms of consequentialism.

\section{A P P E N DIX}

In the main text of my paper, I suggested that it is logically impossible for anyone who actually exists to be better off, equally well off, or worse off than if he or she had never existed and it is logically impossible for anyone who does not exist to be better off, equally well off, or worse off than someone who does. This assumed then that bringing a person into existence could not benefit or harm that person. Parfit has argued that to say that bringing a person into existence could benefit that person is 'not, as some claim, 
obviously mistaken' ${ }^{18}$ Furthermore, we may consider so-called 'wrongful life' suits in which a child takes an action against his or her parents for conceiving him or her whilst knowing that there was a high probability that any child conceived would inherit a serious genetic defect. Such suits may seem to be based on the idea that bringing a person into existence could harm that person. I agree with Parfit that such claims are not obviously mistaken. However, I think that they are nevertheless mistaken and therefore some discussion must be entered into.

It is worth noting that denying that bringing someone into existence could benefit or harm that person does not commit one to denying that killing someone could benefit or (more usually) harm that person. When we see why this is so I think that the temptation to think that bringing someone into existence could benefit or harm them will disappear.

All people who have ever existed, exist now, or will ever exist (from henceforth 'actual' people) have had, have now, or will have, to a greater or lesser extent, the rational desire to lead a fulfilled or 'good' life. It is always worse for persons to have their rational desires frustrated (even if they never know that they have had them frustrated) than it is for them to have them fulfilled and, in a finite lifetime, every actual person will have some such desires which remain, at least partially, frustrated. Therefore, actual persons' deaths are bad as they frustrate their rational desire to lead the good life. ${ }^{19}$ Persons who will never actually exist cannot have desires, rational or otherwise, and thus 'their desires' cannot be frustrated if they are not brought into existence. Bringing persons into existence cannot benefit them and nor can it harm them. This is why actual persons' deaths are (usually) worse for them than their continued living would have been, even though their continued living is never better (or worse) for them than if they had never existed. Thus Williams ${ }^{20}$ is right to say that Sophocles' suggestion that 'Never to have been born counts highest of all' is best met with the ironic Jewish reply 'How many are so lucky? Not one in ten thousand'.

However, it could be suggested that wrongful life suits and the like need not necessarily be predicated on these persons' lives having harmed them;

18 Parfit Reasons and Persons, 487.

19 Here and hereafter I use 'death' as synonymous with 'permanent ceasing to be'. (I argue later that, on the assumption of classical theism, there cannot actually be deaths in this sense. However, this sense is the only one in which it is interesting to maintain that persons' deaths could harm them.) I accept that even in this sense of death, a person's death might not always be worse than the alternatives. Faced with a slow and painful dying, a man might rationally believe that he had no more prospects for leading a fulfilled life this side of the grave; his rational desire for such a life would thus have been frustrated. His continuing to exist in pain might thus actually be worse for him than if he now committed suicide, even if there were no afterlife. (A short fulfilled life with little pain might be a better life for him to have led than a long, equally fulfilled, one with more pain.) However, for most people at most times there is some prospect of the good life, and thus for most people at most times death would mean the unnecessary frustrating of their rational desires. Where the prospect of the good life apparently does not remain, it is bad that it does not appear to remain - as bad indeed as death - but as long as that prospect does remain, death itself would be the greatest evil.

20 Bernard Williams Problems of the Self (Cambridge: Cambridge University Press, i 973), 87. 
they could be predicated simply on these persons' lives being bad, and 'bad enough' to mean that the parents ought not to have generated them. Children born with a genetic defect which condemns them to lives which contain enormous amounts of unremitting and intense pain are children condemned to lead terrible lives. A consequence of accepting the necessary condition for moral indifference advanced in section II might seem to be that we could not blame parents for deliberately bringing into existence children who must (due to a genetic defect) lead terrible lives as, given that no actual persons would be made worse off than they would otherwise have been by the parents' so acting, that condition might seem to suggest that they should be morally indifferent about creating such children. Intuition would suggest that parents are under an obligation not to bring children into existence who are condemned by their genes to lead terrible lives. The classical theist who has such an intuition, yet wishes to stay within the parameters imposed by my argument, must - it might prima facie seem therefore make recourse to the commands of God again; it might seem that he or she would be best advised to suggest that God has commanded that we not deliberately bring into existence people whose lives would be terrible. If the classical theist were to follow such advice, the question would then arise as to whether God had commanded Himself or only His creatures not to bring into existence creatures with terrible lives. If He had not commanded Himself, then He would not have been acting wrongly had He created a universe in which only creatures whose lives were determined to be terrible existed, had He created what I shall call a 'terrible universe'. Such a result might seem implausible. We might therefore think that the classical theist would, if travelling down this road, be further best advised to suggest that God had commanded Himself not to create a terrible universe. Going down this route would thus finally enable the classical theist to reach the conclusion that his or her intuition (that the deliberate creation of creatures destined to lead terrible lives would be bad) was compatible with the necessary condition for moral indifference given in section II.

Apart from the onus which would now fall on the classical theist to show that our universe did not contain a sufficient number of creatures leading terrible lives so as to make its creation incompatible with God's benevolence (an onus which in itself would reveal that the argument in the main body of my paper had failed to provide him or her with all that it had promised), one further unfortunate consequence of following the advice to go down this route would start to become obvious. The sufficient condition for moral indifference endorsed in section II (which would exculpate God from moral responsibility for the creation of this universe) would be being protected from apparent counterexamples with regard to certain human actions (depletion etc.) by an appeal to God's commands to humans with regard to stewardship; it would be being protected from apparent counterexamples with 
regard to other human actions and divine actions (those resulting in the creation of creatures who lead terrible lives or terrible universes) by an appeal to God's command to humans and to Himself. The stewardship commands which the classical theist made mention of in dealing with depletion and so forth were quite localized. However, in proportion to the number of references to God's commands which the classical theist makes to enable him or her to repulse apparent counterexamples concerning terrible lives whilst continuing to present as plausible the principle that something cannot be bad unless it is worse for someone who actually exists than the alternatives - the initial plausibility of the condition that one ought to be morally indifferent if no one would actually be worse off whichever way one acts will be weakened. Not only would the classical theist's argument now need additional supporting argumentation (and a posteriori premises concerning the percentage of actual creatures determined to lead terrible lives), but also the patchwork of divine commands might appear to be in danger of intolerably straining the garment of the plausibility of the condition of moral indifference which it was originally intended to repair.

As a result of this we must, I think, suggest that the classical theist would not be best advised to cope with the apparent counterexamples generated by considerations of terrible lives and terrible universes by extending the ad hoc divine command patchwork. If we could plausibly suggest that the intuitions concerning terrible lives and universes are mistaken or do not require such extensions, then the patchwork would have been kept to a minimum (and in the more obviously acceptable area of stewardship commands to humans); the sufficient condition for moral indifference endorsed in section II would consequently retain more credibility, and the argument of the main text would thus not need supplementing in order to support its resolution to the problem of evil. We can plausibly suggest this.

The intuition that God ought not to be morally indifferent about the creation of a terrible universe is mistaken. The intuition that parents ought not to be morally indifferent about the creation of children who are genetically determined to lead terrible lives is sound, but it does not require extension of the divine command patchwork for explanation.

Supposing God were to create a terrible universe, ex hypothesi this would be a universe in which all people were condemned to go to their graves (I ignore the possibility of immortals such as Tantalus and Sisyphus) with their rational desire to lead the good life almost entirely unfulfilled. Given that it would harm these people to cease to exist permanently whilst their rational desires were unfulfilled, God (in virtue of His being able to) would be morally obliged to ensure that their rational desires were fulfilled in an afterlife. We can plausibly call a person who lives a terrible ante-mortem life and a suitably 'compensating' post-mortem life a person whose overall (i.e. antemortem plus post-mortem) life is 'good', and then we can reasonably suggest 
that if all the residents of a terrible universe were actually destined to have overall lives which were good, then the creation of that universe - by a God whose essential benevolence necessitated that it be conjoined with such a heaven for all its residents - would not have been bad. I suggest that any ante-mortem life of finite duration and finite suffering could in principle be 'compensated' for by the right sort of infinitely extended post-mortem life. (If one is a consequentialist, I do not see how one could disagree with this; if one is not a consequentialist, this claim is nevertheless, I suggest, a plausible one.) Not only would persons destined to have terrible ante-mortem lives and glorious post-mortem lives not be in a worse state than they would have been in had they not been created, in fact (although they would not know this during their ante-mortem lives) their post-mortem lives would compensate for their ante-mortem suffering in the sense of satisfying their previously frustrated desire to lead the good life. Given this, it does not seem unreasonable for the classical theist to suggest that God ought to be morally indifferent about whether or not to create a terrible universe or individual persons destined to lead terrible ante-mortem lives (along of course with their necessary accompaniment, adequate post-mortem compensation). The intuition that God ought not to be indifferent about the creation of persons destined to lead terrible lives is mistaken. It therefore need not be accommodated by the principles endorsed in section II.

Where does this leave human parents with regard to their decision whether or not to deliberately create a child genetically destined to lead a terrible life? We may observe that if such a child were to have been created, then the parents, and society in general, would have an obligation to that child to help it in its suffering. This obligation would be likely to be an onerous one; presumably large amounts of medical care would be required. Therefore, we may justify our intuition that parents ought not to be morally indifferent about creating such a child as, although the child himself or herself would not have been harmed by his or her having been created, the parents themselves and society would have been harmed. They would have been better off if they had not had to cope with the obligations generated by the needs of such a person. Therefore, the intuition that we ought not to deliberately conceive genetically defective children is sound, but it does not require any reference to divine commands to explain it as it is straightforwardly compatible with the principles endorsed in section II. One need not bring in mention of a divine command not to create terrible lives to justify the intuition that we (in contrast to God) ought not to be morally indifferent about doing so.

In conclusion, the classical theist who adopts the argument presented in the main body of this paper is, assuming he or she has certain intuitions about depletion etc., forced into a partial divine command theory. However, neither is he or she forced into a pure divine command theory (which would 
threaten to dissolve rather than resolve the problem of evil); nor is he or she forced to make divine command claims which extend beyond the realm which I have labelled 'stewardship'. If the classical theist has abandoned the libertarian free will defence and moved to the ground of determinism, then such commitments may, I suggest, be considered minimally problematic in enabling him or her to attack consequentialism from a position of strength and repulse Hume's charge. ${ }^{21}$

\footnotetext{
21 I am grateful for the comments of Martha Klein, Galen Strawson, Derek Parfit, and Keith Ward on an early draft of this paper, and to the Editor and two anonymous referees of Religious Studies for their comments on a later version of it.
} 